\title{
NiTi and its Usage in Endodontic Rotary Instruments- A Review
}

\author{
Dr. Mary Sheloni Missier ${ }^{1 *}$, Dr. Ashwin Mathew George ${ }^{1}$
}

\author{
${ }^{1}$ Department of Orthodontics, Saveetha Dental College, Saveetha Institute Of Medical and Technical Sciences, Saveetha University, \\ Chennai, India
}

\author{
DOI: $\underline{10.36347 / \text { sjds.2021.v08i02.002 }}$ \\ | Received: 09.02.2021 | Accepted: 20.02.2021 | Published: 24.02.2021 \\ *Corresponding author: Dr. Mary Sheloni Missier
}

Abstract

Review Article

NiTi plays a major role in the advancement in this specialty, which promotes the quality of the endodontic treatment. With the invention of NiTi, various modifications in the design and flexibility of the endodontic instruments were improved by the surface treatment and thermal treatments. In addition to the advancements in the field of dentistry newer movements of the instruments were incorporated offering greater safety and efficiency during root canal treatment. A better understanding of the mechanical properties of these new NiTi instruments and the efficacy of the instruments on the clinical performance is essential if dental practitioners are to select the instruments that provide optimal clinical outcomes, especially in curved or flattened canals. The objective of this literature review is to discuss the characteristics of the NiTi alloys used in the manufacturing of the endodontic instruments as well as an overall view on the metallurgical and mechanical properties of NiTi instruments used in dentistry.

Keywords: Endodontics; Root Canal Preparation; Dental Instruments.

Copyright $\odot 2021$ The Author(s): This is an open-access article distributed under the terms of the Creative Commons Attribution 4.0 International License (CC BY-NC 4.0) which permits unrestricted use, distribution, and reproduction in any medium for non-commercial use provided the original author and source are credited.

\section{INTRODUCTION}

Niti was invented in 1960 by WH Buehler as he was investigating a alloy in Space Technology vehicle he found that it had a unique property of superelasticy, corrosion resistance and shape-memory. Over the recent years NiTi was used to manufacture endodontic instruments to enhance its flexibility and its resistance to deformation. In endodontics stainless steel instruments were used for canal preparation which had the maximum disadvantage of deformation and instrument separation. After the invention of Nitional they were used to manufacture endodontic instruments because of its unique properties which had many advantages.

When any pressure is applied to an alloy transition from austensitic to martensitic phase occurs such phases occurs even during root canal preparation but when an external force exceeds the given amount of force mechanical slip within the lattice configuration occurs causing permanent deformation occurs but when stress is induced in NiTi alloy, rather than slip [1].

\section{These causes}

A) Volumetric change associated with the transition from one phase to the other and an orientation relation is developed between the phases.
B) The rate of the increase in stress to level off due to progressive deformation. This result causes superelasticity, a similar movement as slip deformation.

C) It springbacks when there is decrease in stress or stops without any permanent deformation. Springback is defined as the load per change in deflection, to the previous shape with a return to the austenite phase, provided that the temperature is within a specific range

\section{Properties of NiTi}

It has two unique properties superelasticity and shapememory.

Other properties - Greater strength

Low modulus of elasticity

Biocompatibility

Resistance to corrosion

Due to these properties they have the advantage of minimal deformation therefore NiTi has been used to manufacture endodontic instruments.

\section{Composition}

The alloy used for the manufacturing endodontic instruments contain

$\mathrm{Ni}-56 \%$

$\mathrm{Ti}-44 \%$ 
In endodontics root canal therapy is the most commonly used treatment to treat the disease of the pulp. One among the procedures in root canal therapy is cleaning and shaping which means removal of the pulp and enlargement of the canal. Earlier cleaning of the canal and shaping was done using conventional instruments which were made using stainless steel and it had maximum amount of deformation, instrument breakage after the invention of NiTi they were used to make endodontic instruments because of its additional unique properties compared to other alloys.

\section{Disadvantages of conventional instruments}

- Greater amount of procedural error

- Not flexible so it cannot be used for cleaning and the shaping of curved canal.

- Preparation of the canal was done with more amounts of transportation and ledge formation

- More amount of chair time

- Due to instrument rigidity more amount of instrument breakage occur

- Greater amount of loss in working length

After the invention of NiTi it was found that it had major advantages than conventional stainless steel so endodontic instruments were manufactured to overcome these disadvantages of conventional instruments.

\section{Advantages of endodontic NiTi instruments}

Reduction in procedural errors-due to its superelastic property there was less instrumental breakage

\section{Resistance to clockwise torsional stress}

It is 3 times more flexible compared to stainless steel so that it could be used for curved canals

\section{Canal preparation can be done with less transportation and ledge formation}

Engine driven NiTi instruments reguire less chair time compared to stainless steel which is 6 times lesser amount of time taken by stainless steel instruments

- Less loss of working length

- Reduced file fracture

- Reduced apical transportation due to its flexibility

\section{Construction of the endodontic instruments}

Manufacturing of NiTi instruments are more complex compared to manufacturing stainless steel instruments, the superelasticity of this alloy does not allow spiral structure as they do not undergo permanent deformation [1, 2]. So when the alloy is being manufactured the finished $\mathrm{NiTi}$ wires go through various procedures before they are manufactured into endodontic instruments. Initially the casting alloy is drawn into cylindrical shape before it is exposed to under pressure to draw them into wires, then the formed wires are exposed to even pressure to form a tapered shape by using a number of rollers. Other procedures such as drawing the wire into cone shape, annealing was carried simultaneously which is followed by shaping the wire into a required shape before cleaning and conditioning of the wire and then it is stored in reels.

\section{Movements used in mechanical canal preparation}

The normal mechanical endodontic preparation has been made easy with the invention of NiTi endodontic instruments by reducing the working time and by decreasing the stress delivered during shaping of the canal. The centric rotary motion was invented in the year 1980 which lead them to utilise electric motors in the field of endodontics thereby reducing the contraangled handpiece usage thereby it helped in reducing instrument fracture during reshaping the canal of the tooth by counterclockwise rotation followed by clockwise rotation the NiTi files.

\section{Reciprocating movement}

In a study [3] canal preparation for all types of canal was done using F2 Pro-Taper in different angles of rotation in the clockwise and counter-clockwise direction by exerting mild apical pressure. Therefore this study led to the understanding that no longer sequential filing is required for reshaping the canal which led to the development of single-filing technique by various companies which had two motions counterclockwise rotation and clockwise rotation. Counterclockwise rotation to cut the dentin whiles the clockwise rotation to clear the cut dentin.

In 2016 Genius system was introduced they had S-shaped cross-section which is made of NiTi alloy which is thermally treated thereby it led to the benefit that the present system is torsional fracture resistant when compared to former system. This was followed by Sybron system, Twisted adaptive file system, Optimal reverse torque motion system, pro-taper system, trushape system each had its own mechanism which differed from each system based on these previous system SAF (Self-Adjusting File) was invented by $\mathrm{Re}$ Dent-Nova in 2010 which is made of NiTi structure having abrasive surface which reduced the instrumentation time to 4 min per canal.

\section{CONCLUSION}

The technological advancements in the recent years paved way for major progress in the field of endodontic therapy. With the invention of NiTi it led to the development of rotary endodontics which reduced the timing taken for shaping the canal although in earlier days of invention it had the risk of instrument separation during treatment with the incorporation of newer motion strategy the rate of instrument separation was reduced. Studies proved that in endodontics centric rotary instrument upto a certain percentage of the walls are not touched during endodontic treatment whereas the eccentric rotary instruments has more balanced 
dentin contact therefore greater amount of instrument cyclic fatigue resistance. Recent studies state that the heat treated NiTi have increased flexibility therefore they can be bent accordingly to the shape of the canal but they have greater deformation capacity. Even though there is various innovations there are no endodontic rotary instrument which meets the entire requirement for an ideal canal preparation. Therefore newer studies should be done to develop a system which has good efficiency as well as safety instrumentation.

\section{REFERENCES}

1. Thompson SA. An overview of nickel-titanium alloys used in dentistry. International endodontic journal. $2000 \mathrm{Jul} ; 33(4): 297-310$.

2. Andreasen GF, Hilleman TB. An evaluation of 55 cobalt substituted Nitinol wire for use in orthodontics. The Journal of the American Dental Association. 1971 Jun 1;82(6):1373-5.

3. Yared G. Canal preparation using only one Ni- $\mathrm{Ti}$ rotary instrument: preliminary observations. International endodontic journal. 2008 Apr;41(4):339-44. 